\title{
Reconfigurable RF MEMS PIFA Antenna: A Review Study
}

\author{
Priyanka Jain ${ }^{1}$, Shubhi Jain ${ }^{2}$ \\ ${ }^{1}$ Department of Electronics and Communication Engineering, ACEIT Jaipur (INDIA) \\ ${ }^{2}$ Department of Electronics and Communication Engineering, Swami Keshvanand Institute of Technology, \\ Management \& Gramothan, Jaipur, Rajasthan (INDIA) \\ Email: prija.jain@gmail.com, shubhijain19@gmail.com \\ Received 06.02.2021, Received in revised form 19.03.2021, Accepted 04.04.2021
}

\begin{abstract}
RF MEMS switching devices are very important for reconfigurable antenna signal and its paths. This paper presents the review study of four different reconfigurable antenna that employs $\mathrm{RF}$ Micro-Electro- Mechanical Systems (RF MEMS) technology simultaneously with bandwidth enhancement techniques.

The RF MEMS switch can operate at $0.1-40 \mathrm{GHz}$ frequency range. The thickness of cantilever, gap of electrodes are some parameter of switches by varying these parameters the performance of switches can changed. Every design is fabricated and compare with simulated one. The simulation and measured result shows the good degree of agreement. The parameter comparison is also done in this paper.
\end{abstract}

Keywords- RF MEMS switch, cantilever, inductive effect, capacitive effect, Reconfigurable antenna

\section{INTRODUCTION}

As the communication system grows day by day there is demand of new RF technology for improving system capacity. In this field wireless communication plays a vital role. There are many applications required different frequency bands and size is the main constraint of these types of devices[1-2]. As a result reconfigurable circuits are more durable in these situations. Reconfigurable antenna systems are designed with characteristics such as frequency band, radiation pattern for different plane and gain. RF (Radio frequency) MEMS (Micro-Electro-Mechanical-System) is a method to integrate and combine electrical and mechanical mechanism. Now a day's RF MEMS switch are very important for merging the technology of electrical and mechanical systems [34]. RF MEMS devices have many applications in different areas as military, telecommunication and signaling due to its wide band width and low less signals. In previous years transistor, PIN diode and other traditional switches are popular but now a day's RF MEMS switches are popular by reason of high linearity, low power consumption, low insertion loss and high isolation.

RF MEMS switch can be designed to work on 0.1 $\mathrm{GHz}$ to $40 \mathrm{GHz}$ frequency. The size of RF MEMS switches is $1 \mu$ to $1 \mathrm{~mm}$ [5-6]. With these applications RF MEMS PIFA antenna is reviewed here for many applications. This paper is lined up with background in section-II, designs in section-III and comparisons in section-IV. Section-V concludes this paper.

\section{BACKGROUND}

The introduction of micro machine membrane is come in picture on 1979 where many type of MEMS switches are made using different type of actuation mechanisms. Classification of these switches is done in the form of metal contacting and capacitive coupling. Capacitive coupling switches have thin dielectric plates and air-gap between them whereas metal contacting switches have ohmic contact in electrodes [7, 8]. From that time MEMS switches take a tremendous progress in microwave switching field. Capacitive switches are most popular in industries now days. To achieve higher bandwidth and gain without effecting efficiency RF MEMS switches are used. In this paper four designs are reviewed and compared to show how RF MEMS PIFA antennas are useful for us.

\section{DESIGN PARAMETER}

\subsection{Design-1}

In this design a PIFA antenna is designed on Ansoft HFSS. The antenna layout is shown in figure 1 . The folded PCB is used here of a rohcell block material of polyimide for fabrication of antenna. coaxial feeding technique is used to provide power to antenna at center point of design.

Capacitor Switch MEMS is placed under the antenna on two dies according to figure 1. For PCB interconnections bond wires are used and for reimburse the design issues during making circuit a little variation is allowed in designing. After designing the result shows for $765-950 \mathrm{MHz}$ the $\mathrm{S} 11$ is below $6 \mathrm{~dB}$ and results a wide bandwidth. $22 \%$ better bandwidth is achieved in result from simulation. 


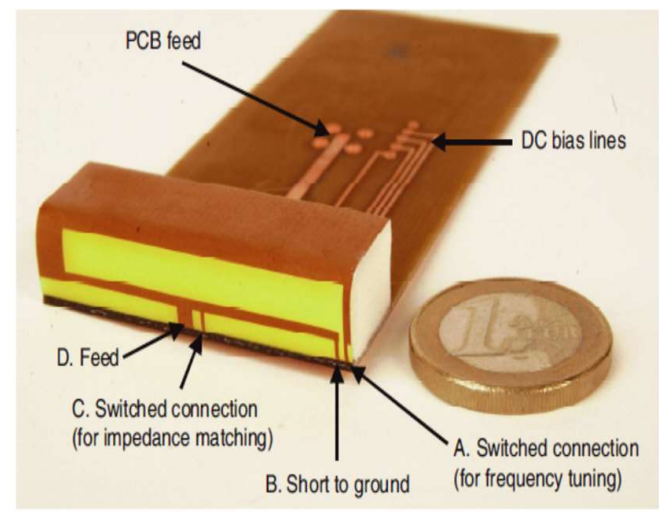

Fig.1 MEMS switched PIFA and PCB

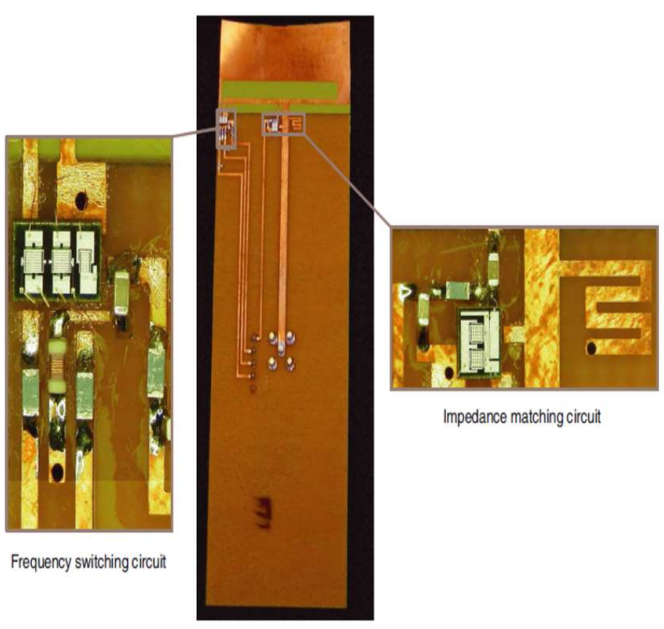

Because of some discontinuity in fabrication process all three bands (1930-2062 MHz , 1941-2071 MHz and $2005-2117 \mathrm{MHz}$ ) are not getting higher bandwidths more than $6 \mathrm{~dB}$ which is required. For higher bandwidths inductive matching can be applied after which more than $300 \mathrm{MHz}$ bandwidth is achieved. For high frequency modes resonance frequency is shifts but it is less than simulated. For removing the differences simulation and measurement the capacitive density of MEMS switches should be increased by using long bond wires. The fabricated antenna shows several modes of operation and over them a band is having greater bandwidth than one octave.

\subsection{Design-2}

The proposed antenna is fabricated on R04003 substrate with dielectric constant $\square \mathrm{r}=3.38$, tangent loss $\tan \delta=0: 002$ with air between two layer of substrate. The antenna worked on two frequency modes $718 \mathrm{MHz}$ and $4960 \mathrm{MHz}$. the lower layer of antenna design used MEMS switch as reconfigurable metal layer and upper layer is working as top patch of antenna. When meander is connected with patch it is working for $718 \mathrm{MHz}$ and when it is not connected it is working for $4960 \mathrm{MHz}$. A substrate of R04003 is placed between upper and bottom layer of antenna to produce the inductive effect of coaxial feed. The layer has a thickness of $0.813 \mathrm{~mm}$ and the distance of layer is $5.5 \mathrm{~mm}$.

Fig.2 Unfolded antenna and details of MEMS dies and surrounding components.

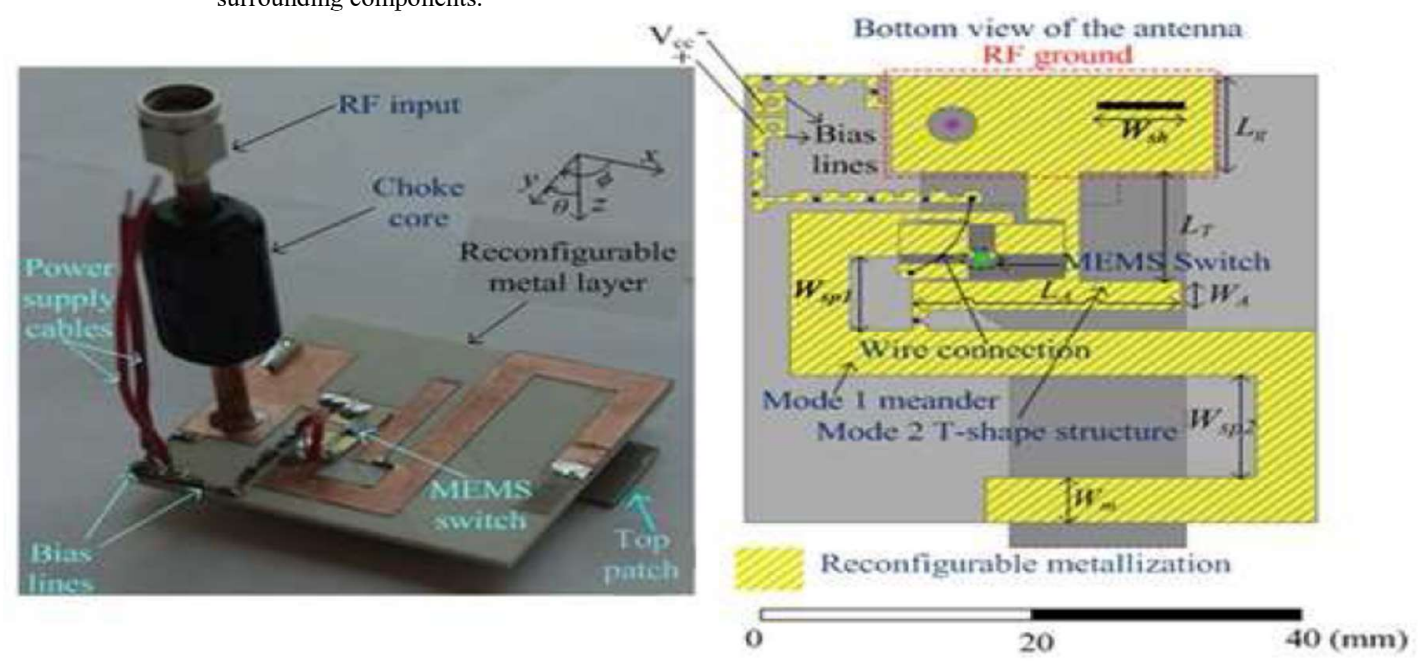

Figure. 3: The photographs and schematics of the RF MEMS integrated antenna depicting the critical design parameters.

The comparison between theoretical and measured result shows the good degree of agreement. According to the performance antenna has a wide bandwidth of $2.6 \%$ at $718 \mathrm{MHz}$ with very small dimension. The radiation pattern shows the good result of both frequency modes.

\subsection{Design-3}

In this antenna design a $\mathrm{T}$ - shaped ground layer is designed on its pole. The ground layer have all type of MEMS switches which work as major radiating element for changing the resonance frequency. 
Antenna has three working modes which can be switched by RF MEMS switches. The first mode for antenna is at $160 \mathrm{MHz}$ frequency which is optimize to resonate to this frequency by a meandered line. Group one and three switches are always on in this mode and group four switch is closed. One another meander line also added in the design which is working as sub meander to make resonance separate at $160 \mathrm{MHz}$ frequency. For second mode group two and three switches are on and other switches are off. This mode is working on $450 \mathrm{MHz}$ frequency and provides a straight path for signal. For achieving the required bandwidth the pole width is attuned. Mode 3 having the center frequency of $800 \mathrm{MHz}$ and keeping two modes without interruption only group two switches are open in this mode. Fig 5 shows the fabricated antenna. The measured result shows the good performance impedance bandwidth is increased $7 \%, 11 \%$, and $19 \%$ for three modes.

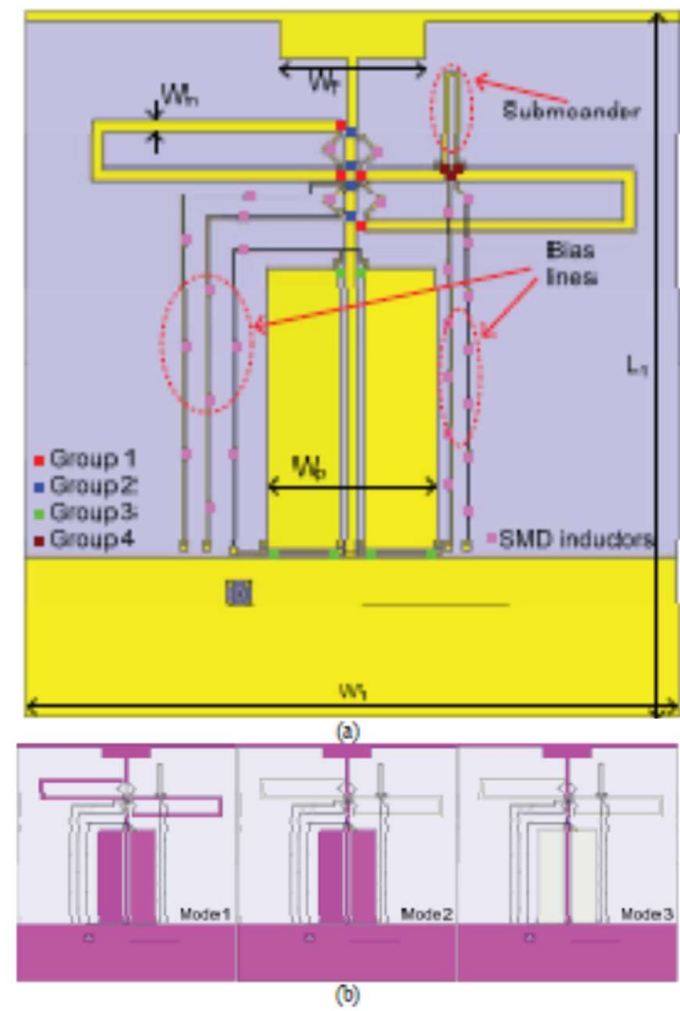

Fig. 4 (a) The top view of the reconfigurable ground plane (b) The active parts of the ground layer in all three modes of operation.

\section{RESULT AND CONCLUSION}

Design-1 worked on five different frequency band in which $\mathrm{S} 11$ is below $6 \mathrm{~dB}$ for $760-950 \mathrm{MHz}$ and for second frequency $830 \mathrm{MHz}$ it gives bandwidth of $22 \%$ more and for other three bands 1930-2062 $\mathrm{MHz}, 1941-2071 \mathrm{MHz}$ and $2005-2117 \mathrm{MHz} 6 \mathrm{~dB}$ bandwidth is achieved. Design-2 shows the antenna works on two frequency bands $718 \mathrm{MHz}$ and 4960 $\mathrm{MHz}$ and it gives $2.6 \%$ increment in bandwidth on $\lambda / 10 x \lambda / 10$ small dimension. Design -3 also works on three frequency bands which are $160 \mathrm{MHz}$, $450 \mathrm{MHz}, \quad 800 \mathrm{MHz}$ and after measurement bandwidth is increased on these bands are $7 \%, 11 \%$, and $19 \%$.

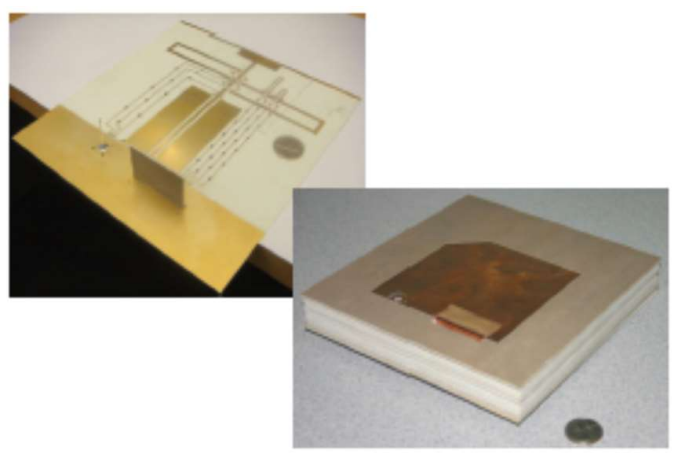

Fig.5 (a) Photograph (b) SEM of the fabricated ohmic contact, series RF MEMS switch.

\section{REFERENCES}

[1] Kiriazi, J., H. Ghali, H. Ragaie, and H. Haddara, "Reconfigurable dual-band dipole antenna on silicon using series MEMS switches," Proceedings of the IEEE Antennas and Propagation Society International Symposium, Vol. 1, $403\{406,22\{27$ June 2003.

[2] Panaia, P., C. Luxey, G. Jacquemod, R. Staraj, G. Kossiavas, L. Dussopt, F. Vacherand, and C. Billard, "MEMS-based recon gurable antennas," Proceedings of the IEEE International Symposium on Industrial Electronics, Vol. 1, 175-179, 4-7 May 2004.

[3] Onat, S., M. Unlun, L. Alatan, S. Demir, and T. Akin, "Design of a re-con gurable dualfrequency microstrip antenna with integrated RF MEMS switches," Proceedings of the IEEE Antennas and Propagation Society International Symposium, Vol. 2A, $384\{387,3\{8$ July 2005.

[4] Rijks, T. G. S. M., et al., "Passive integration and RF MEMS: a toolkit for adaptive LC circuits," Proceedings of the 29th European Solid-State Circuits Conference, 269272, 16-18 Sept. 2003.

[5] Van Beek, J. T. M., et al., "High-Q integrated RF passives and micromechanical capacitors on silicon," Proceedings of the Bipolar/BiCMOS Circuits and Technology Meeting, 147-150, 28-30 Sept. 2003.

[6] De Graauw, A. J. M., P. G. Steeneken, C. Chanlo, J. Dijkhuis, S. Pramm, A. van Bezooijen, H. K. J. ten Dolle, F. van Straten, and P. Lok.," Proc. BCTM2006, 2006.

[7] A. Khoshniat, H. S. Mopidevi, and B. A. Cetiner, "Broadband capacitively fed tapered type PIFA with modified ground plane, “ IEEE Electronics Letters, vol. 46, no. 7, pp. 474-475, Apr. 2010.

[8] G.M. Rebeiz, "RF MEMS Theory, Design, and Technology", John Wiley \& Sons, Inc., New York, NY, 2003.

[9] Wicht Technologie Consulting (WTC), "The RF MEMS Market 2002-2007: Analysis, Forecasts and Technology Review," http://www.wtc-consult.de, 2002.

[10] P.M. Zavracky, N.E. McGruer, R.H. Morrison, and D. Potter, "Microswitches and Microrelays with a View Toward Microwave Applications," International Journal of RF and Microwave Computer Aided Design, vol. 9, no. 4, pp. 338-347, July 1999

[11] Y.Nafde and R.Pande, "Design and Analysis of Reconfigurable Antenna Using RF MEMS and Fractal Geometry", Advanced Computer and Communication Engineering Technology, Springer LNEE, Vol 362, pp 
1249-1261, 2016.

[12] Y.Nafde and R.Pande, "Performance Analysis of Reconfigurable USlot Fractal Antenna for Wireless Applications", submitted for inclusion in IEEE Explorer and presented in the IEEE WISPNET 2016 ,EEE international conference held at SSN college, Chennai,India during 23-25 March 2016.

[13] A.H.Ramadan, K.Y.Kabalan, A.El-Hajj, S. Khoury \& M.Al-Husseini "A Reconfigurable U Koch Microstrip Antenna for Wireless Applications" Progress In Electromagnetic Research, PIER, pp.355- 367, 2009. Proceedings of the 2016 IEEE Students' Technology Symposium 